\title{
Kinetics and Morphology of Electrochemical Vapour Deposited Thin Zirconia/Yttria Layers on Porous Substrates
}

\author{
H. W. Brinkman, J. Meijerink, K. J. de Vries \& A. J. Burggraaf \\ Department of Inorganic Materials Science, Faculty of Chemical Technology, University of Twente, PO Box 217, \\ 7500 AE Enschede, The Netherlands
}

(Received 2 May 1995; accepted 9 September 1995)

\begin{abstract}
By means of electrochemical vapour deposition $(E V D)$, it is possible to grow thin $(0.5-5 \mu \mathrm{m})$, dense zirconia/yttria layers on porous ceramic substrates. Kinetics of the EVD process, morphology and oxygen permeation properties of the grown layers are investigated. Very thin $(\sim 0.5 \mu \mathrm{m})$ layers are grown at relatively low temperatures $\left(700-800^{\circ} \mathrm{C}\right)$. Water vapour as reactant enhances the surface reaction rate at the solid oxide/oxygen source reactant interface. $A$ transition occurs from pore diffusion (above $1000^{\circ} \mathrm{C}$ ) to bulk electrochemical diffusion (below $900^{\circ} \mathrm{C}$ ) as ratelimiting step for layer growth. The zirconialyttria solid solution is mainly deposited in the cubic phase; the layers grow in a typical columnar way and are polycrystalline. Oxygen permeation measurements show that the oxygen permeation flux through the zirconialyttria layers is influenced by the layer thickness, morphology, presence of water vapour and the oxygen pressure gradient over the layer.
\end{abstract}

\section{Introduction}

The (clectro)chemical vapour deposition technique (abbreviated as CVD/EVD) was originally developed by Westinghouse Electric Corporation (Pittsburg, USA) to form thin, gas-tight, solid electrolyte [e.g. yttria-stabilized zirconia, (YSZ)] layers on porous substrates for solid oxide fuel cells (SOFC). Electrolyte layers with a thickness of $2-50 \mu \mathrm{m}$, deposited at $1000-1100^{\circ} \mathrm{C}$, have been reported. ${ }^{1-3}$ More recently proposed applications of $\mathrm{CVD} /$ EVD-grown layers are their use in oxygen sensors, electrocatalytic reactors and as oxygen separation membranes. In the ideal case, in dense oxygen semipermeable membranes (without pinholes or cracks) the selectivity for oxygen should be infinite, since oxygen is the only compound that can permeate through. In the case that the bulk diffusion of oxygen ions is the rate-limiting step in the separation process, membrane layers should be as thin as possible to obtain a maximum oxygen permeation rate.

The principles of the CVD/EVD technique have been outlined extensively in the literature. ${ }^{1-4} \mathrm{~A}$ mixture of metal chlorides $\left(\mathrm{ZrCl}_{4}\right.$ and $\mathrm{YCl}_{3}$, generated in the 'chloride chamber') is kept separate from an oxygen source reactant (water vapour, oxygen or a mixture, generated in the 'water chamber') by a porous ceramic substrate. Initially, under proper process conditions, the reactants diffuse into the substrate pores and react to form a metal oxide (zirconia-yttria solid solution or ZY) which deposits on the pore wall. As this process continues, pore narrowing occurs until at a certain moment the pores become totally plugged with the metal oxide. The above-mentioned stages are together known as the opposite reactant CVD (ORCVD) stage, and this stage has been discussed, for example, in Refs 5 and 6. Layer or film growth in the subsequent EVD stage is only possible in metal oxides with mixed (i.e. ionic and electronic) conducting behaviour. The oxygen source reactant is reduced at the oxygen source/film interface; oxygen ions (counter-balanced by electrons or co-balanced by electron holes) migrate through the growing film to the film/metal chloride interface, where they react at this interface with the metal chlorides to form (again) the metal oxide. These sequential steps in the EVD stage are shown in Fig. 1.

This paper deals with the kinetics and morphology of zirconia/yttria layers, grown by means of EVD on porous ceramic substrates. In the past few years, only a few groups have investigated the kinetics for the growth of YSZ by means of EVD. Only Westinghouse Electric Corporation (Isenberg ${ }^{1}$ and $\mathrm{Pal}$ and Singhal ${ }^{7}$ ), Carolan and Michaels, ${ }^{8}$ Burggraaf and co-workers, ${ }^{4,9-11}$ Schoonman and co-workers, ${ }^{12-16}$ 


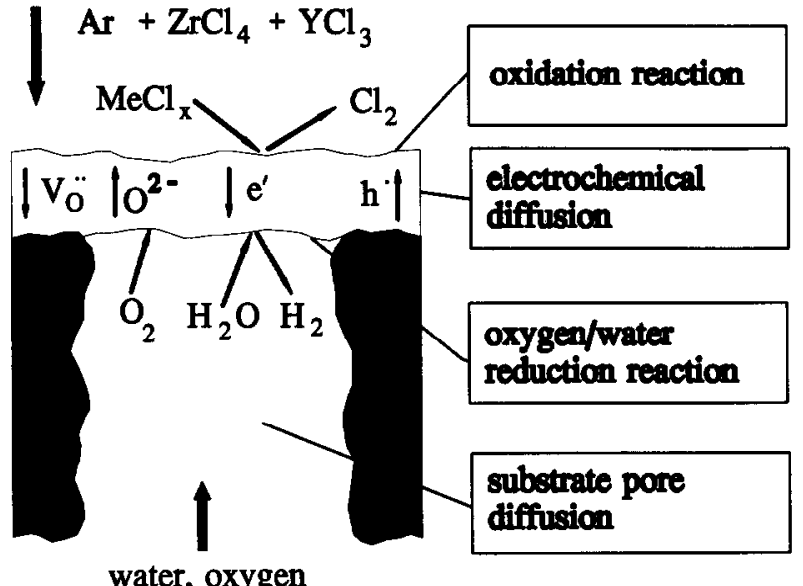

water, oxygen

Fig. 1. Schematic view of the four steps in the EVD process.

Sasaki et al. ${ }^{17}$ and Han and $\operatorname{Lin}^{18}$ have reported these investigations. In Ref. 15 a short, systematic discussion is given on the EVD kinetics for YSZ layer growth. Some discrepancies in EVD data have been reported. Among others, Pal \& Singhal ${ }^{7}$ and Carolan \& Michaels ${ }^{8}$ have found that the EVD process obeys a parabolic law, in which the film thickness is proportional to the square root of the deposition time. On the other hand, for example Isenberg ${ }^{1}$ showed that the deposited film thickness of YSZ doped with a small amount of $\mathrm{CeO}_{2}$ was a linear function of time.

In this paper the optimum process conditions are investigated for growing zirconia/yttria layers that are as thin as possible on porous substrates. Therefore, the influence of the deposition temperature on the film growth rate on a 'model' substrate is investigated. The EVD process is influenced by temperature, since it relies on the electronic and ionic conductivities that are strongly temperature dependent. When the limiting step for the growth of the YSZ layer is diffusion through the bulk, and when bulk properties hold for thin layers, layer growth at $800^{\circ} \mathrm{C}$ is expected to be much slower than at $1000^{\circ} \mathrm{C}$. Due to the large value of the activation energy for electronic conduction in YSZ as reported in Ref. 19, the diffusion resistance in the YSZ film at $800^{\circ} \mathrm{C}$ is three orders of magnitude larger than that at $1000^{\circ} \mathrm{C}$. This would theoretically imply that when a deposition experiment is performed at $800^{\circ} \mathrm{C}$, the YSZ layer will grow very slowly after reaching the stage of pore plugging. This indicates that very thin $(<1 \mu \mathrm{m})$ dense YSZ layers can be grown on porous substrates. In the current investigation, deposition mainly occurs at $700-800^{\circ} \mathrm{C}$. Besides the influence of temperature, also the influence of the addition (or removal) of water as oxygen source reactant and the influence of substrate geometries are investigated.

The experimental work performed by Lin et $a l .^{10}$ focused on the effects of oxygen partial pres- sure and substrate pore dimensions on the EVD film growth rate. Experiments were mainly performed on $\alpha$-alumina substrates (thickness $2 \mathrm{~mm}$, average pore diameter $160 \mathrm{~nm}$ ) at $1000^{\circ} \mathrm{C}$ and a total pressure of 2 mbar. $\mathrm{H}_{2} / \mathrm{H}_{2} \mathrm{O}$, dry air and moist air were used as oxygen source reactant. Experimental results combined with theoretical predictions showed that the substrate pore diffusion was the rate-limiting step for layer growth in the first $\sim 5 \mathrm{~h}$, for the $\alpha$-alumina substrates mentioned above (with water-containing oxygen source reactants). This linear growth rate was $\sim 1.5 \mu \mathrm{m} \mathrm{h}^{-1}$. For a composite substrate with a larger pore diameter/ pore length ratio (factor of 15000 larger compared with $\alpha$-alumina), the growth rate was $32 \mu \mathrm{m}$ $\mathrm{h}^{-1}, 20$ times that of $\alpha$-alumina. Lin et al. suggested that substrate pore diffusion was still the rate-limiting step for this composite substrate. Their data indicated that the oxygen partial pressure at the oxygen source side did not have much influence on the layer growth rate. However, the presence of water had a substantial influence as can be seen in experimental data shown in Refs 9 and 10 .

Morphologic aspects such as gas-tightness, phase- and microstructure of EVD-grown ZY layers are reported in the present paper. These aspects have a large influence on the performance of the devices mentioned above via material properties such as conductivity and oxygen permeability. Gas-tight layers are important for oxygen separation membranes; only then is the selectivity for oxygen infinite. The optimum in ionic conductivity in bulk YSZ is found for compositions with about 8-10 mol\% $\mathrm{Y}_{2} \mathrm{O}_{3}$ with the cubic fluorite phase (at room temperature). Zirconia/yttria solid solutions with less yttria consist of tetragonal or monoclinic phases which are hardly or not ionic conducting. The microstructure of very thin layers with layer thickness comparable to the crystallite size $(\leq 1$ $\mu \mathrm{m})$ is important since grain boundary effects (transport of, e.g., oxygen along the crystallite boundaries) and crystallite orientation and/or columnar structures may play an important role.

A major characterization technique used here is (in situ) oxygen permeation since a possible application of EVD-grown layers is as oxygen separation membranes. Besides, investigation of the oxygen permeation through EVD-grown YSZ films may help in understanding the mechanism for oxygen permeation through thin electrolyte films.

\section{Experimental}

EVD experimental conditions and procedures

Most experiments were performed in a home-built CVD/EVD reactor, known as the MM1 (mem- 
Table 1. Characteristics of substrates used in CVD/EVD experiments

\begin{tabular}{lc}
\hline Coarse porous $\alpha$-alumina substrate & \\
Diameter $(\mathrm{mm})$ & 12 \\
Thickness $(\mathrm{mm})$ & 2 \\
Mean pore diameter $(\mu \mathrm{m})^{a}$ & $0 \cdot 16$ \\
Porosity $(\%)^{a}$ & 50 \\
& \\
La-doped $\gamma$-alumina membrane & \\
Diameter $(\mathrm{mm})$ & $12(12)$ \\
Thickness & $5 \mu \mathrm{m}(2 \mathrm{~mm})$ \\
Mean pore diameter & \\
Porosity $(\%)^{d}$ & $20 \mathrm{~nm}(0 \cdot 16 \mu \mathrm{m})$ \\
\hline
\end{tabular}

"Measured by means of mercury intrusion porosimetry.

"Data of top layer; support data between brackets.

'Measured by means of permporometry.

"Measured by means of nitrogen adsorption-desorption.

brane modifier 1) reactor. An extensive description of this reactor together with the experimental procedure to deposit zirconia/yttria on porous substrates is given in Refs 4 and 5 . In this section a brief outline is given of the deposition conditions and procedures.

A porous alumina substrate, either a coarse porous $\alpha$-alumina substrate or a composite system consisting of a La-doped $\gamma$-alumina supported by an $\alpha$-alumina substrate (the characteristics of both systems are given in Table 1), was mounted onto the end of a dense alumina tube, separating the reactor into two chambers. In the case of the composite system, the $\gamma$-alumina membrane top layer faced towards the metal chloride chamber. The preparation and characterization of these substrates is extensively described elsewhere..$^{20,21}$ The temperature inside the MM1 reactor was controlled by a six-zone furnace and an additional heating tape. Before an experiment was started, the zones were heated to their desired temperatures. When the temperature profile had been established, about $30 \mathrm{~min}$ before the experiment started, the sublimation beds were filled with fresh $\mathrm{ZrCl}_{4}$ and $\mathrm{YCl}_{3}$ powder, and the beds were placed at the correct position in the reactor so that metal chloride vapours were generated with a sufficiently high vapour pressure. Ar or $\mathrm{N}_{2}$ gas flows were passed through the sublimation beds to carry the metal chloride vapours to the porous substrate. At the other side of the porous substrate, a water/air mixture (ratio 1/1) was generated by bubbling air through a water sparger.

The influence of deposition temperature on the layer growth rate was investigated with coarse porous $\alpha$-alumina substrates and is reported in Ref. 22. Process conditions are shown in Table 2. First, $1 \mathrm{~h}$ of deposition was performed at $800^{\circ} \mathrm{C}$. Then the temperature was kept at $800^{\circ} \mathrm{C}$ or raised to 900 or $1000^{\circ} \mathrm{C}$, and deposition continued for a variable period of time $(1 \cdot 5,3$ or $4 \mathrm{~h})$.
Table 2. Typical CVD/EVD experimental conditions for the MM1 reactor

\begin{tabular}{lc}
\hline Deposition temperature $\left({ }^{\circ} \mathrm{C}\right)$ & $700-1000$ \\
Reactor pressure $(\mathrm{Pa})$ & 200 \\
$\mathrm{ZrCl}_{4}$ sublimation bed temperature $\left({ }^{\circ} \mathrm{C}\right)$ & 150 \\
$\mathrm{YCl}_{3}$ sublimation bed temperature $\left({ }^{\circ} \mathrm{C}\right)$ & 625 \\
$\mathrm{Ar}$ carrier gas flow rate through $\mathrm{ZrCl}_{4}$ bed & \\
{$\left[\mathrm{ml}(\mathrm{STP}) \mathrm{min}^{-1}\right]$} & 15 \\
$\mathrm{Ar}$ carrier gas flow rate through $\mathrm{YCl}_{3}$ bed & $7 \cdot 5$ \\
{$\left[\mathrm{ml}(\mathrm{STP}) \mathrm{min}^{-1}\right]$} & 40 \\
Water sparger temperature $\left({ }^{\circ} \mathrm{C}\right)$ & \\
Air carrier gas flow rate through water sparger & $3 \cdot 5$ \\
{$\left[\mathrm{ml}(\mathrm{STP})\right.$ min $\left.^{-1}\right]$} & 15 \\
Total pressure in water sparger $(\mathrm{kPa})$ & $1 / 1$ \\
Air/water ratio in vapour & \\
\hline
\end{tabular}

A small number of deposition experiments was performed in another CVD/EVD reactor, known as the MM2 (membrane modifier 2) reactor, to investigate the influence of the presence of water as oxygen source reactant. Detailed experimental procedures for these deposition experiments are extensively described elsewhere. ${ }^{23}$ One experiment was performed for $2 \mathrm{~h}$ on an $\alpha$-alumina substrate at $1000^{\circ} \mathrm{C}$ deposition temperature and 5 mbar reactor pressure with a $1 / 1$ water/air mixture as oxygen source reactant and $\mathrm{ZrCl}_{4} / \mathrm{YCl}_{3}$ as metal chloride reactants. Another experiment was performed in exactly the same way, but now the water supply was disconnected so that only air was used as oxygen source reactant while the deposition time was $2.5 \mathrm{~h}$.

To obtain dense zirconia/yttria layers that were as thin as possible, a number of deposition experiments was performed at $700^{\circ} \mathrm{C}$ on La-doped $\gamma$-alumina membrane composites. Lin et. al. ${ }^{9}$ stated that the minimum thickness of a dense EVD-grown YSZ film depends on the average pore size (distribution) of the substrate surface on which the film grows. They reported films as thin as $0.2-0.5 \mu \mathrm{m}$, grown at $1000^{\circ} \mathrm{C}$ on La-doped $\gamma$-alumina membrane composites of which the top layer had a thickness of $\sim 3 \mu \mathrm{m}$ and an average pore diameter of $10 \mathrm{~nm} .{ }^{9}$ Typical deposition times are 30-120 min under conditions shown in Table 2. In situ oxygen permeation experiments were performed with these very thin layers within a few hours after the deposition had ended (see section 'In situ oxygen permeation experiments'). Besides the depositions on membrane composites at $700^{\circ} \mathrm{C}$, an additional number of depositions have been performed both on membrane composites and coarse porous substrates at higher temperatures. These samples were also used for in situ oxygen permeation.

A number of experiments was performed in the MM1 reactor at $800^{\circ} \mathrm{C}$ on $\alpha$-alumina substrates under conditions mentioned in Table 2 to investi- 
gate morphological aspects such as gas tightness of the layers, phase composition and crystallite size. Deposition times at $800^{\circ} \mathrm{C}$ were varied between 30 and $240 \mathrm{~min}$, also to investigate the pore closure time for the $\alpha$-alumina substrate. These results were compared with morphological results of layers grown at higher temperatures (e.g. $1000^{\circ} \mathrm{C}$ ).

\section{Characterization of the deposited layers}

The gas tightness of CVD/EVD-grown layers was checked in two ways. The first check, which was performed in situ in the CVD/EVD reactor, was to get a rough indication of the gas tightness. The metal chloride room was filled with $\sim 200$ mbar argon while the water chamber was filled with 100 mbar argon. When the pressure in the water chamber increased with time this was considered to be an indication that the YSZ layer was not fully gas tight. The second way to check the gas tightness was performed in a home-made helium permeation apparatus as is described in Ref. 24.

By means of a scanning electron microscope [(SEM) Jeol JSM-35CF)] connected to a Kevex Delta-class EDX analyzer for energy dispersive $\mathrm{X}$-ray analysis, the thickness of the EVD-grown layers was estimated. The real layer thickness was found by the back-scattered electron image (BEI) and the formed phases (elements) were checked by EDX.

The phase structure, composition, layer thickness and crystallite size of the CVD/EVD-grown zirconia/yttria layers were investigated by X-ray diffraction [(XRD) Philips PW1710 using $\mathrm{Cu} K_{\alpha}$ radiation] and SEM. During XRD analyses, samples were measured between $2 \theta=20$ and $90^{\circ}$ with scan step in the range $2 \theta=0.015-0.03^{\circ}$; the intensity at each point was collected during 5-10 s. Additional high resolution analyses for morphological aspects were performed by means of high resolution scanning electron microscopy [(HRSEM) Hitachi S800 field emission microscope] and atomic force microscopy [(AFM) Nanoscale II].

Of one EVD sample, grown at $1000^{\circ} \mathrm{C}$ for $6 \mathrm{~h}$ on a gel-cast porous $\mathrm{Sr}_{0.15} \mathrm{La}_{0.85} \mathrm{MnO}_{3}$ substrate (thickness $2 \mathrm{~mm}$, average pore diameter $0.9 \mu \mathrm{m}$, porosity $67 \%$ ) in another $\mathrm{CVD} / \mathrm{EVD}$ reactor (known as SOFC reactor), the zirconia/yttria layer peeled off. This layer was examined by transmission electron microscopy [(TEM) Philips CM30 operating at $300 \mathrm{kV}$ ] and the selected area electron diffraction facility connected to it to estimate the crystallite size and the crystallographic phases. The sample was pretreated by dimple grinding and ion milling. In this way the crystallite size found by TEM was compared with the crystallite size found by XRD to investigate the reliability of latter method.

\section{In situ oxygen permeation experiments}

After the EVD film growth process several samples were used for in situ oxygen permeation experiments; this process has already been described. ${ }^{9}$ The main advantage of this in situ process (i.e. performed in the CVD/EVD reactor) is that high temperature sealing processes and other problems related with transport of an EVD-grown sample to an oxygen permeation apparatus are avoided.

The CVD/EVD experiments were performed at $700^{\circ} \mathrm{C}$ for $30 \mathrm{~min}$ under conditions as shown in Table 2. The gas tightness of the deposited layers was checked by in situ argon permeation (see section 'Characterization of the deposited layers'), and when they showed some leakage another 30 min of deposition followed. This procedure was followed until the layers were gas tight. In almost all cases the layers were gas tight after $30 \mathrm{~min}$ deposition. Then the zone of the furnace in which the sample was placed was heated to the desired temperature $\left(700-1000^{\circ} \mathrm{C}\right)$ to perform an in situ oxygen permeation measurement. When this temperature was reached, another in situ argon permeation measurement was performed to check whether the rise in temperature caused some leakage. The temperature of the sublimation beds was lowered (for $\mathrm{ZrCl}_{4}<100^{\circ} \mathrm{C}$, for $\mathrm{YCl}_{3}<300^{\circ} \mathrm{C}$ ) and in some cases the sublimation beds were removed from the furnace. The presence or absence of sublimation beds did not influence the in situ oxygen permeation values according to our experience. When the sample was still gas tight, a standard in situ oxygen permeation measurement was performed. The water chamber was flushed with oxygen and the chloride chamber with argon for about $5 \mathrm{~min}$. Then the water chamber (volume $\left.375 \mathrm{~cm}^{3}\right)$ was filled with pure oxygen $(150 \mathrm{mbar}$, so $\left.P_{\mathrm{O}_{2}}=0.15 \mathrm{~atm}\right)$ and the chloride chamber (volume $\left.>>375 \mathrm{~cm}^{3}\right)$ with argon (150 mbar; nominal $\left.P_{\mathrm{O}_{2}}=10^{-5} \mathrm{~atm}\right)$. During $30-45 \mathrm{~min}$ the pressure decrease in the water chamber (due to oxygen permeation through the EVD YSZ sample) was measured. With each sample a blank permeation (i.e. 150 mbar argon in both chambers) was performed to correct for possible leaks from the outside.

In a first series of in situ oxygen permeation experiments the relative error in the measurements was rather large (about 30-60\%), mainly due to scatter, so that only an order of magnitude for the oxygen permeation value could be obtained. In further in situ oxygen permeation experiments the volume of the water chamber was decreased to $267 \mathrm{~cm}^{3}$ by inserting a voluminous metal body inside this chamber. Now the error in the measurements was smaller $(\sim 10 \%)$.

Besides performing in situ oxygen permeation 
with oxygen vs. argon, one experiment was performed with a water/oxygen mixture vs. argon. Also, some in situ permeation experiments were performed on several samples both immediately after the EVD process had ended and the day after. This was done to investigate the influence of time on the permeation results.

\section{Results and Discussion}

By means of the CVD/EVD technique it is very well possible to grow thin, dense zirconia/yttria films on porous alumina substrates. Layers are grown on the side of the substrate exposed to the metal chloride vapours. A typical SEM photograph of a cross-section of a zirconia/yttria layer deposited on a porous $\alpha$-alumina substrate for $10 \mathrm{~h}$ at $1000^{\circ} \mathrm{C}$ under conditions of Table 2 is shown in Fig. 2 (sample \#91041). The layer has a thickness of $\sim 5 \mu \mathrm{m}$ and has a columnar-like structure which is typical for EVD-grown zirconia/yttria layers on porous supports at high temperature. Crystallites on the surface of the layer are highly faceted; this can be seen even better in Fig. 3, where a SEM photograph of the surface of the same sample as in Fig. 2 is shown. The average size of the surface crystallites here is in the range of 2 to $3 \mu \mathrm{m}$. XRD analyses showed that the formed layers consisted mostly of the cubic YSZ phase, but also some amounts of monoclinic and tetragonal phases (up to about $40 \%$ ) were observed.

A rough estimate of the gas tightness of the deposited zirconia/yttria layers was performed by in situ argon permeation immediately after the EVD process had stopped. In almost all cases the grown layers were gas tight (within the measurement accuracy, \pm 0.5 mbar in $5 \mathrm{~min}$ ) after deposition for 30 to $240 \mathrm{~min}$ at $700-1000^{\circ} \mathrm{C}$ under conditions as are shown in Table 2. Performing in situ argon permeations the day after, when the

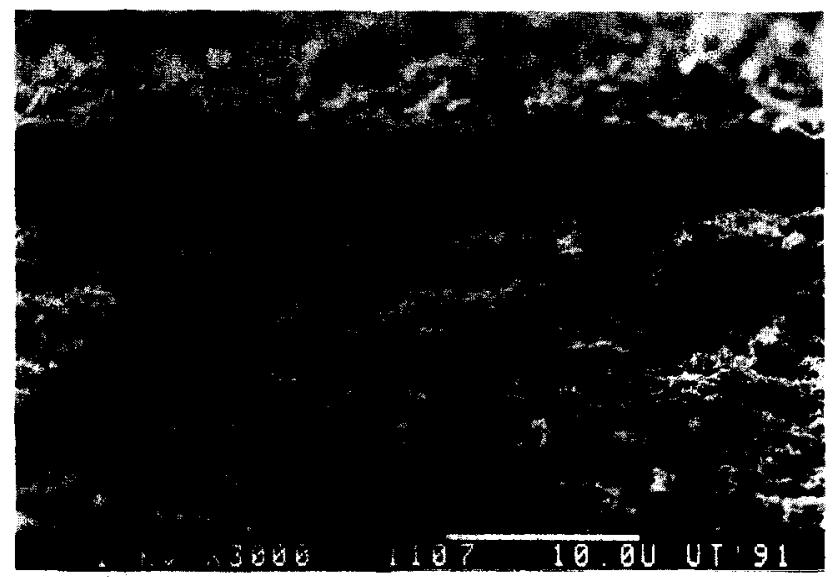

Fig. 2. SEM photograph of a cross-section of a zirconia/yttria layer deposited on porous $\alpha$-alumina.

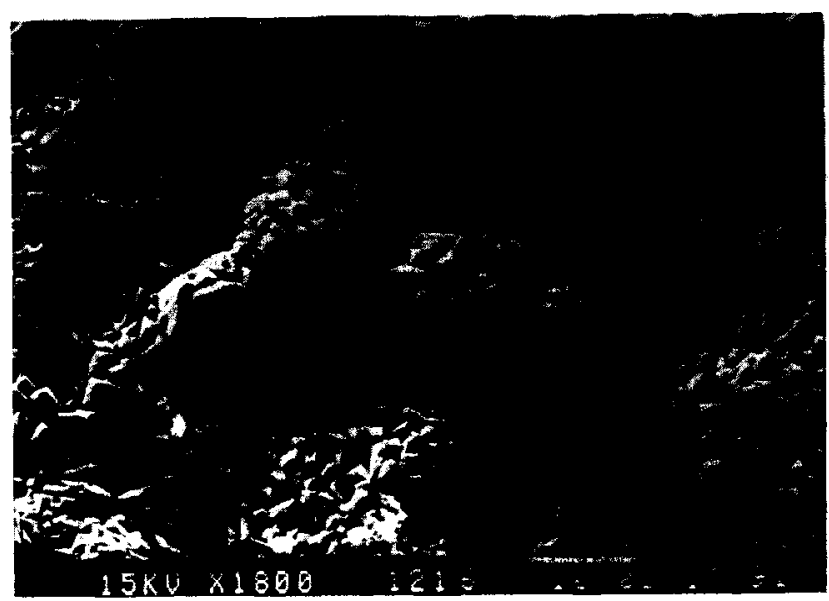

Fig. 3. SEM photograph of the highly faceted surface of an EVD-grown zirconia/yttria layer.

furnace had cooled to room temperature, showed in several cases some leakage. Further investigations showed that this was due to the fact that the ceramic seal (Autostic) between the porous substrate and the dense alumina water chamber tube became porous after cooling. The deposited samples themselves remained gas tight after cooling.

Detailed information about helium permeation experiments through $\alpha$-alumina substrates deposited at $800^{\circ} \mathrm{C}$ under conditions as described in Table 2 is presented in Ref. 24. The pore closure time (i.e. the time at which the ORCVD stage ends and the EVD stage begins) is estimated to be around 40 min. This value is slightly higher than the pore closure time for $\alpha$-alumina substrates, deposited at $1000^{\circ} \mathrm{C}$ and 2 mbar reactor pressure. ${ }^{4}$

\section{Kinetics of EVD growth of zirconia/yttria layers}

Zirconia/yttria layers have been grown with and without water present in the water chamber, under otherwise equal process conditions (MM2 reactor, deposition temperature $1000^{\circ} \mathrm{C}$, reactor pressure 5 mbar). According to XRD analysis, both EVDgrown layers had the cubic yttria-stabilized zirconia structure. Deposition for $2 \mathrm{~h}$ with an air/water vapour mixture gave a YSZ layer with thickness 4-6 $\mu \mathrm{m}$. Deposition for $2.5 \mathrm{~h}$ without water vapour resulted in a layer thickness of $0 \cdot 5-1 \mu \mathrm{m}$. The influence of water vapour on the YSZ layer growth rate is obvious. Including a pore closure time of $30 \mathrm{~min}$ (for zirconia/yttria deposition at $1000^{\circ} \mathrm{C}$ and $2 \mathrm{mbar}^{4}$ ) this means that the layer growth is around 0.4 and $3 \mu \mathrm{m}$ per hour in the absence and presence of water vapour, respectively. So the layer growth rate is decreased by almost a factor 10 in the absence of water! The presence of water apparently influences the rate-limiting step for YSZ layer growth. Wen and Mason ${ }^{25}$ reported the influence of water vapour on the cathodic reduction of oxygen on scandia-stabilized zirconia 
coated with a porous gold electrode. The following mechanism, based on suggestions made by them, may be responsible for incorporating oxygen ions $\left(\mathrm{O}^{2-}\right)$ into stabilized zirconia in the presence of water $\left(\mathrm{H}_{2} \mathrm{O}\right) ; \mathrm{H}_{\mathrm{i}}$ is an interstitial proton:

$$
\begin{aligned}
& \mathrm{H}_{2} \mathrm{O}(\mathrm{g}) \rightleftharpoons \mathrm{O}^{2-}+2 \mathrm{H}_{\mathrm{i}} \\
& 2 \mathrm{H}_{\mathrm{i}} \rightleftharpoons \mathrm{H}_{2}(\mathrm{~g})+2 \mathrm{~h}
\end{aligned}
$$

When the diffusion of the oxygen source reactant (i.e. oxygen or water) through the pores is the rate-limiting step for EVD layer growth, the following equation can be used for theoretically predicting the layer growth rate $\mathrm{d} l / \mathrm{d} t$, assuming that the oxygen (or water vapour) partial pressure in the chloride chamber is negligible compared with the partial pressure of the oxygen source reactant in the water chamber (see, for example, eqns (18) and (19) in Ref. 10):

$$
\frac{\mathrm{d} l}{\mathrm{~d} t}=\frac{V_{\mathrm{mol}} n_{i} D_{i} P_{i, \mathrm{OSR}}}{2 L R T}
$$

Here $i$ is water or oxygen, and $n_{i}$ is equal to 1 for water and 2 for air, including the effect that water contains one oxygen atom per molecule whereas air (i.e. molecular oxygen) contains two oxygen atoms per molecule. $V_{\text {mol }}$ is the (average) molar volume of YSZ inside the layer, $D_{i}$ is the Knudsen diffusion coefficient for compound $i, P_{i, \mathrm{OSR}}$ is the vapour pressure of compound $i$ at the pore entrance, $L$ is the substrate thickness (or pore length), $R$ is the gas constant and $T$ is the temperature.

The experimental values found above may be compared with theoretical results from eqn (2). The Knudsen diffusion coefficients for water and oxygen at $1000^{\circ} \mathrm{C}$ are respectively $1.3 \times 10^{-5}$ and $1.0 \times 10^{-5} \mathrm{~m}^{2} \mathrm{~s}^{-1}$, assuming that the $\alpha$-alumina substrate has a porosity of $50 \%$ and a tortuosity value of 2.5 . In the MM2 reactor, operating at $1000^{\circ} \mathrm{C}$ and 5 mbar total pressure, the partial water vapour pressure in the presence of water is $2.5 \mathrm{mbar}$ (water/air, ratio 1/1). In the absence of water, the oxygen partial pressure is 1.05 mbar (air at 5 mbar). When pore diffusion is rate-limiting, the zirconia/yttria layer growth would be around 5.8 and $3.5 \mu \mathrm{m} \mathrm{h}^{-1}$ in the presence and absence of water, respectively. For the situation in which water is present, the theory is in agreement with the experiment (almost a factor 2 difference), but for the situation in which only air is present, the theory does not agree with the experiment (almost one order of magnitude difference).

In conclusion it can be said that diffusion of the water-vapour-containing oxygen source reactant through the substrate pores is rate-limiting for EVD zirconia/yttria layer growth at $1000^{\circ} \mathrm{C}$ in the
Knudsen area (low pressure, small pores). Apparently, the presence of water enhances the surface reaction rate at the metal oxide/oxygen source reactant interface. When the oxygen source reactant contains no water, another step (for example, a surface exchange reaction) may be rate-limiting.

The results of the experiments in which zirconia/ yttria layers are deposited as a function of total deposition time on $\alpha$-alumina substrates for different deposition temperatures are discussed in Ref. 22. The observed layer growth rates, obtained from the slope of straight lines of layer thickness vs. total deposition time, are $1.6 \mu \mathrm{m} \mathrm{h}^{-1}$ (at $1000^{\circ} \mathrm{C}$ ), $0.4 \mu \mathrm{m} \mathrm{h}^{-1}$ (at $900^{\circ} \mathrm{C}$ ) and around $0 \mu \mathrm{m} \mathrm{h}^{-1}$ (at $800^{\circ} \mathrm{C}$ ). Due to the relatively large inaccuracy (especially at $800^{\circ} \mathrm{C}$ ) this does not mean that the layer growth really obeys a linear growth rate behaviour. Although at $1000^{\circ} \mathrm{C}$ a linear relation for the layer growth is very probable, at lower temperatures other relations between the layer thickness and the total deposition time will also hold within the measurement errors. Compared with previous results, the values for the layer growth rate obtained here are almost equal. In previous papers ${ }^{4,10}$ it was found that the layer growth rate at $1000^{\circ} \mathrm{C}$ and 2 mbar was about 1.5 $\mu \mathrm{m} \mathrm{h}^{-1}$; the value of $1.6 \mu \mathrm{m} \mathrm{h}^{-1}$ reported here is within the measuring error.

The rate-limiting step for the layer growth process was evaluated in a similar way as done before in our group, ${ }^{10,11}$ where it is suggested that one may calculate the film growth rate for each of the steps assuming it is rate-limiting. In the first place the surface exchange reactions are excluded; in the presence of water it is assumed that the surface exchange rate at the water side is fast enough, as was discussed above. Further, the facts that faceted crystallites were grown (see e.g. Fig. 3) and that the layer growth was not noticeably dependent on the metal chloride partial pressure ${ }^{9}$ give the impression that the oxidation reaction at the metal chloride side is not a rate-limiting step. Pal and Singhal ${ }^{7}$ have used substrates with large pores ( $10 \mu \mathrm{m}$, estimated from a SEM photograph) and found an almost perfect straight line when the square of the YSZ film thickness was plotted against the deposition time, indicating that only (the electronic part of) the electrochemical diffusion process in the layer was rate-limiting.

When the bulk electrochemical transport in the EVD film is the rate-limiting step, eqn (3) displays the theoretical temperature dependence ( $T$ in $\mathrm{K}$ ) of the layer growth rate $\mathrm{d} l / \mathrm{d} t$ as derived in Ref. 22.

$\frac{\mathrm{d} l}{\mathrm{~d} t}=6.8 \times 10^{4} T \mathrm{e}^{-19379(\mathrm{~K}) / T}+3.8 \times 10^{14} T \mathrm{c}^{-45024(\mathrm{~K}) T}$ 
Equation (4), also from Ref. 22, displays the theoretical temperature dependence of $\mathrm{d} l / \mathrm{d} t$ when substrate pore diffusion is rate-limiting:

$$
\frac{\mathrm{d} l}{\mathrm{~d} t}=\frac{82}{\sqrt{T}}\left(\mu \mathrm{m} \mathrm{h}^{-1}\right)
$$

According to these equations it follows that the theoretical transition temperature (from pore diffusion as the rate-limiting step to electrochemical diffusion as the rate-limiting step) is around $825^{\circ} \mathrm{C}(1100 \mathrm{~K})$. In Ref. 22 it is stated that it is very probable that the diffusion of the water/air mixture through the substrate pores is the ratelimiting step for EVD film growth at $1000^{\circ} \mathrm{C}$. At $900^{\circ} \mathrm{C}$ the bulk electrochemical diffusion through the zirconia/yttria layer is most probably the ratelimiting step. Extrapolating to lower temperatures, this is also the case at $800^{\circ} \mathrm{C}$. At $800^{\circ} \mathrm{C}$ a quantitative discrepancy exists between theory and experiment: theoretically a layer growth rate (bulk diffusion limiting) of $\sim 1 \mu \mathrm{m} \mathrm{h}^{-1}$ is expected, while experimentally the maximum layer growth rate is only a few tenths of a $\mu \mathrm{m}$. $\Lambda \mathrm{t} 900^{\circ} \mathrm{C}$ a discrepancy exists too; according to theory, pore diffusion is the rate-limiting step, while according to the experiments bulk diffusion is rate-limiting. There are several possible causes for these discrepancies. One possibility is that the oxygen partial pressure in the chloride chamber is higher than $10^{-17} \mathrm{~atm}$, which is the assumed value in Ref. 22 . But for a good agreement between theory and experiments, a high $P_{\mathrm{O}, \mathrm{McCl}}$ is necessary (only a few orders of magnitude lower than $P_{\mathrm{O}, \mathrm{OSR}}$ ). It is not likely, however, that the oxygen partial pressure in the chloride chamber is that high. To illustrate this, Pal and Singhal reported an oxygen partial pressure as low as $4.3 \times 10^{-18} \mathrm{~atm}$ in the chloride chamber. ${ }^{7}$ Another possibility to explain the discrepancy between theory and experiment is that the formed EVD layers were not totally cubic but also consisted of the monoclinic and tetragonal ZY phases. The effective values of the electron and electron-hole conductivities of cubic YSZ [present in the pre-exponential factors in eqn (3)] are then lower because the relative amount of cubic YSZ is smaller than unity (as is the fact in Ref. 19). Of course, it is also possible that data generated in Ref. 19 for YSZ bulk material may no longer hold for thin layers with a different morphology.

Very thin zirconia/yttria layers were deposited on La-doped $\gamma$-alumina membrane composites at $700^{\circ} \mathrm{C}$ under conditions as described in Table 2 . Typical deposition times were $30 \mathrm{~min}$. Layers as thin as about $0.5 \mu \mathrm{m}$ were found to be gas tight as was checked by in situ argon permeation and helium permeation. Our experience is that layers

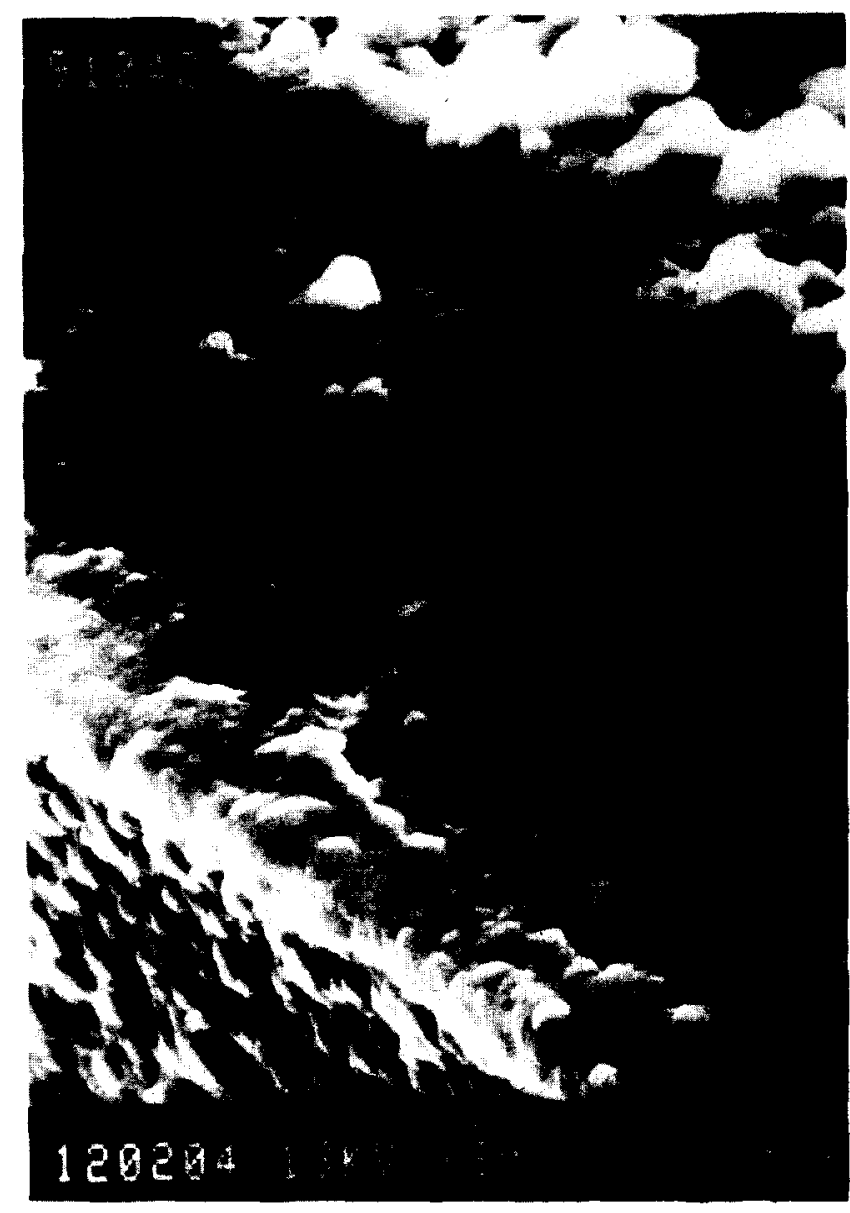

Fig. 4. HR-SEM photograph of a zirconia/yttria layer deposited for $120 \mathrm{~min}$ at $700^{\circ} \mathrm{C}$ on La-doped $\gamma$-alumina membrane. Bottom left: ZY layer (thickness $\sim 0.5 \mu \mathrm{m}$ ), middle: $\gamma$-alumina membrane (thickness $\sim 3 \mu \mathrm{m}$ ), upper right: $\alpha$-alumina support.

could not be made thinner than several tenths of a $\mu \mathrm{m}$ (on these substrates) without showing some gas leakage. These results confirm those of Ref. 9, where thin $(0.5 \mu \mathrm{m})$ zirconia/yttria layers were grown after $30 \mathrm{~min}$ on La-doped $\gamma$-alumina membrane composites at $1000^{\circ} \mathrm{C}$, at similar process conditions as in Table 2. These EVD-grown layers were further used in in situ oxygen permeation experiments, since the very thin zirconia/yttria layers were expected to have high oxygen permeation values. A typical HR-SEM photograph of a dense zirconia/yttria layer deposited at $700^{\circ} \mathrm{C}$ for 120 min on a membrane composite is shown in Fig. 4.

\section{Morphology of the deposited layers}

The morphology of layers deposited at $800^{\circ} \mathrm{C}$ for 30 to $240 \mathrm{~min}$ under conditions as described in Table 2 is discussed here. In the XRD patterns of porous $\alpha$-alumina substrates on which zirconia/ yttria is deposited, several phases are observed. An example of such an XRD pattern is shown in Fig. 5 (\#92032, $120 \mathrm{~min}$ deposition). Besides the $\alpha$-alumina phase of the substrate, several zirconia/ yttria phases are present: monoclinic, tetragonal and/or cubic. The $\alpha$-alumina peaks are sharp, while 


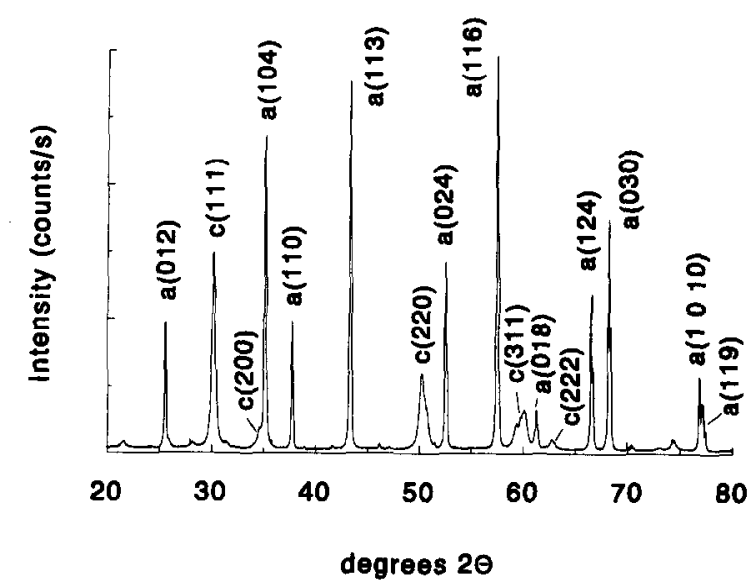

Fig. 5. XRD pattern of EVD-grown sample \#92032. Cubic YSZ (c) and $\alpha$-aluminia (a) peaks are indexed.

the zirconia/yttria peaks are rather broad; these peaks are indexed in Fig. 5.

It was very hard to distinguish between the tetragonal and cubic phases. In theory, the small (400) type reflections in the $2 \theta$ region between 73 and $75^{\circ}$ are different for the tetragonal and cubic phases. In the CVD/EVD-grown samples this can hardly be seen, since the $(400)$ peaks are small and the $\alpha$-alumina (208) peak is also located in this range, which makes the analysis very difficult. However, both the tetragonal phase (see, for example, Ref. 26) and the cubic phase (see, for example, Ref. 19) exhibit oxygen ion conductivity. The bulk conductivities are similar for both phases; the grain boundary conductivity of the tetragonal phase is, however, much less. ${ }^{27}$ Hence, with the tetragonal phase present it is preferred to have only a few grain boundaries across the layer thickness. The monoclinic zirconia/yttria phase can be easily distinguished from the tetragonal or cubic phase; the monoclinic (i 111$)$ and (1 111$)$ peaks at $2 \theta=$ 28.2 and $31.5^{\circ}$ differ from the tetragonal/cubic (111) peak around $2 \theta=30^{\circ}$. The non-linear calibration method $^{28,29}$ was used to calculate the volume fraction of monoclinic zirconia/yttria; this procedure is outlined in a previous publication from our group. ${ }^{24}$ A computer algorithm was used for processing the

Table 3. Effects of deposition time and temperature on the volume fraction of monoclinic zirconia/yttria

\begin{tabular}{lccc}
\hline Sample \# & $\begin{array}{c}\text { Deposition } \\
\text { temperature }\left({ }^{\circ} \mathrm{C}\right)\end{array}$ & $\begin{array}{c}\text { Deposition time } \\
(\text { min })\end{array}$ & $V_{m}($ vol\% $)$ \\
\hline 92030 & 800 & 30 & $7 \cdot 8$ \\
92031 & 800 & 45 & $6 \cdot 7$ \\
92029 & 800 & 60 & $13 \cdot 0$ \\
92032 & 800 & 120 & $1 \cdot 2$ \\
92047 & 800 & 240 & $5 \cdot 1$ \\
$90105^{a}$ & 1000 & 120 & $\sim 0$ \\
91025 & 1000 & 120 & $\sim 0$ \\
$91027^{b}$ & 1000 & 120 & $\sim 0$ \\
\hline
\end{tabular}

${ }^{a} \phi_{\mathrm{Ar} . \mathrm{ZrCl}_{4}}=7.5 \mathrm{ml}(\mathrm{STP}) \mathrm{min}^{-1} ; \phi_{\mathrm{Ar}_{\mathrm{YCCl}}}=30 \mathrm{ml}(\mathrm{STP}) \mathrm{min}^{-1}$.

${ }^{b} T_{\mathrm{YCl}_{3}}=650^{\circ} \mathrm{C}$.
XRD data of the CVD/EVD-grown layers as outlined in Ref. 30.

In Table 3 the fraction of monoclinic zirconia/ yttria is shown as a function of the deposition time. As can be seen from the table, the fraction of monoclinic phase is rather small, between 0 and $13 \mathrm{vol} \%$. In a previous publication from our group $^{24}$ these values were a factor of 2-3 higher due to a wrong interpretation and calculation procedure. When the volume fraction of monoclinic phase, deposited at $800^{\circ} \mathrm{C}$, is compared with that deposited at $1000^{\circ} \mathrm{C}$ under nearly the same conditions (samples \#90105, \#91025 and \#91027 in Table 3), the monoclinic volume fraction is higher when the temperature is lower under current process conditions. The reason for this might be that the concentration ratio $\mathrm{YCl}_{3} / \mathrm{ZrCl}_{4}$ near the substrate is lower at $800^{\circ} \mathrm{C}$ than at $1000^{\circ} \mathrm{C}$. At a deposition temperature of $1000^{\circ} \mathrm{C}$, the $\mathrm{YCl}_{3}$ bed (nominal temperature $625^{\circ} \mathrm{C}$ ) can be heated additionally by radiation coming from the deposition zone, which is rather close to this bed. The $\mathrm{ZrCl}_{4}$ bed is much less influenced by this deposition zone since the distance is larger, so the ratio $\mathrm{YCl}_{3} / \mathrm{ZrCl}_{4}$ can be higher than expected. When this ratio is the same in the gas phase and in the EVD-grown layers, less monoclinic zirconia/yttria will be expected in the layers at $1000^{\circ} \mathrm{C}$.

From Fig. 5 it has been observed that the zirconia/ yttria peaks were more broadened than the $\alpha$-alumina peaks. In previous publications ${ }^{24,31}$ this broadening has been ascribed to the existence of a very small grain size, assuming that no line broadening occurred due to local inhomogeneities and strain. The Scherrer equation ${ }^{32}$ can be used to calculate the crystallite size $D$ from the broadening of YSZ reflections (indexed in Fig. 5), assuming that broadening is only due to size:

$$
D=\frac{K \lambda}{\beta_{\mathrm{CS}} \cos \theta} \frac{360}{2 \pi}
$$

$\lambda$ is the wavelength of $\mathrm{Cu} K_{\alpha_{1}}$ radiation $(0 \cdot 15405$ $\mathrm{nm}), \theta$ is the diffraction angle of the $(h k l)$ reflection, $K$ is a constant $(0.94)$ and $\beta_{\mathrm{CS}}$ is the half width at half maximum of a step-scan profile of the $(h k l)$ peak after correction for $K_{\alpha_{1}}-K_{\alpha_{2}}$ separation and instrumental broadening. For the samples mentioned in Table 3 which were deposited at $800^{\circ} \mathrm{C}$, the value of the (instrumental corrected) line broadening of the YSZ (111) peak around $2 \theta$ $=30^{\circ}$ was in the range $2 \theta=0.35$ to $0.50^{\circ}$, slightly increasing with decreasing deposition time. This corresponds to a crystallite size of 17 to $25 \mathrm{~nm}$, so very small. The same crystallite sizes hold for samples deposited at $1000^{\circ} \mathrm{C}$ in Table 3 . However, this line broadening cannot be ascribed completely to the existence of small crystallites. Inhomogeneities 
(i.e. the existence of more than one phase) also play a role in the occurrence of line broadening. For example, the 'assumed to be YSZ' peak around $2 \theta=30^{\circ}$ consists of cubic and tetragonal parts too. Besides the existence of small crystallite sizes and inhomogeneities, another cause for line broadening is strain in the material. Thin zirconia/ yttria layers which were grown at high temperatures and cooled to room temperature may contain a considerable amount of strain since the thermal expansion coefficient is different from that of $\alpha$-alumina. Accordingly, it is not possible to say anything about crystallite sizes by $\mathrm{X}$-ray line broadening, since other phenomena also influence the line broadening.

By means of TEM it was possible to determine the crystallite size of EVD-grown layers. The 'peeled off' YSZ layer, described in the 'Experimental' section $\left(6 \mathrm{~h}\right.$ deposition at $1000^{\circ} \mathrm{C}$ on a $\mathrm{Sr}_{0.15} \mathrm{La}_{0.85} \mathrm{MnO}_{3}$ substrate), consisted of crystallites with sizes between 1 and $5 \mu \mathrm{m}$; most crystallites had a size of 2-3 $\mu \mathrm{m}$. These sizes were roughly equal in all dimensions, so columns were not observed. This indicates that columns in the columnar-like structures, observed by SEM for samples grown at high temperatures $\left(1000^{\circ} \mathrm{C}\right.$, see

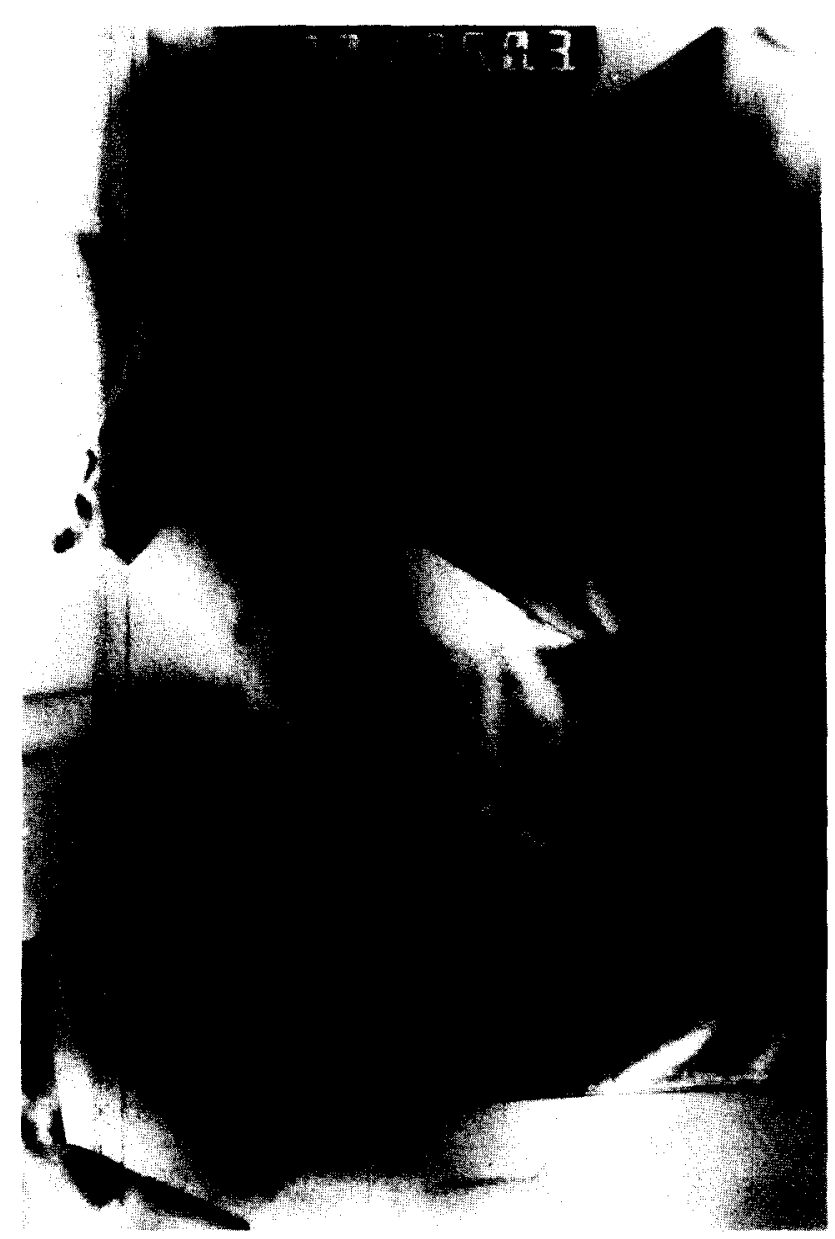

Fig. 6. TEM photograph of YSZ crystallites (text bar at the top $=1.4 \mu \mathrm{m})$. Deposition conditions: $6 \mathrm{~h}$ at $1000^{\circ} \mathrm{C}$ on $\mathrm{Sr}_{0.15} \mathrm{La}_{0.85} \mathrm{MnO}_{3}$ substrate.

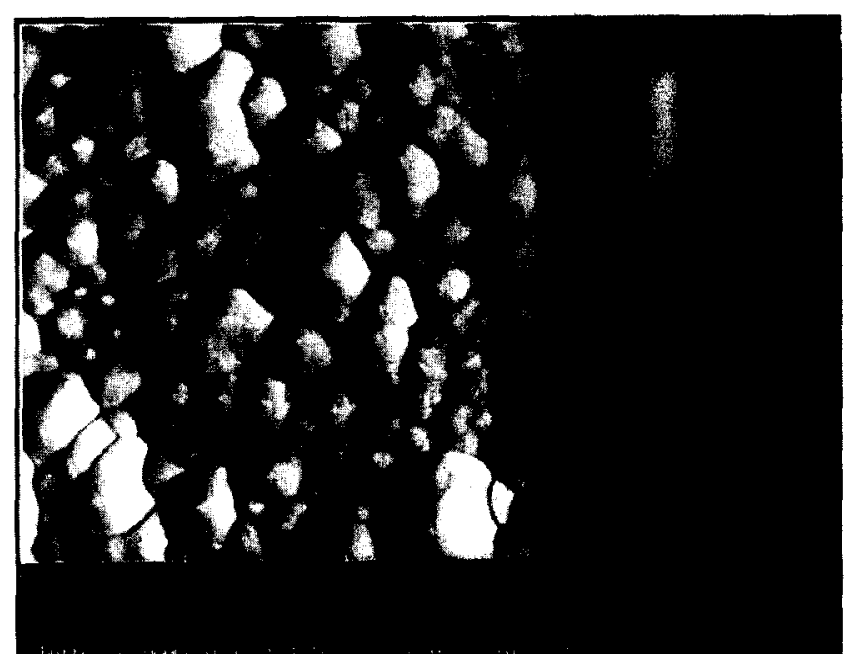

Fig. 7. AFM picture of the surface of an EVD-grown zirconia/ yttria layer (\#91123).

e.g. Fig. 2), consisted of smaller crystallites. A typical TEM photograph is shown in Fig. 6. Selected area electron diffraction revealed the cubic YSZ phase. By means of SEM, similar crystallite sizes were observed at the surface of the EVD-grown layer. This suggests that the crystallites inside the layer and at the surface of the layer are same size, about 2-3 $\mu \mathrm{m}$. Crystallites with sizes as small as $15-25 \mathrm{~nm}$ were not observed by TEM, indicating that the crystallite size found by $\mathrm{X}$-ray line broadening is not correct.

Sample \#91123 (2 h deposition at $1000^{\circ} \mathrm{C}$ on an $\alpha$-alumina substrate under standard conditions) was investigated by AFM to estimate the crystallite size. A typical AFM picture is given in Fig. 7, and by means of AFM investigation the crystallite size was found to be between 0.1 and $0.7 \mu \mathrm{m}$. By means of SEM similar crystallite sizes were found. Crystallites with sizes as small as $15-25 \mathrm{~nm}$ were not observed.

These two results suggest that there might be some influence of experimental conditions (i.e. deposition temperature, deposition time, substrate type) on the apparent crystallite size. Sample \#91042 (2 h deposition at $700^{\circ} \mathrm{C}$ on La-doped $\gamma$-alumina membrane) resulted in a zirconia/yttria layer with a thickness of $\sim 0.5 \mu \mathrm{m}$ and an average

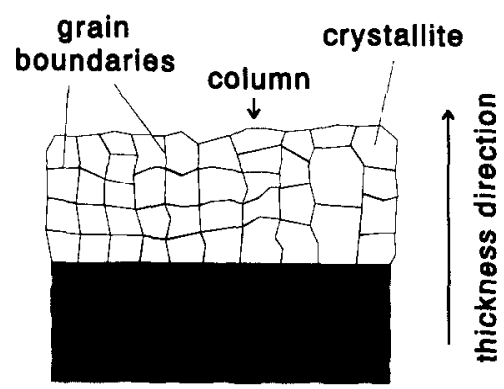

Fig. 8. Schematic view of a cross-section of a zirconia'yttria layer on a porous substrate. 
(surface) crystallite size of $\sim 0.1-0.2 \mu \mathrm{m}$. Surface crystallites of sample \#91123, deposited for $2 \mathrm{~h}$ at $1000^{\circ} \mathrm{C}$ on an $\alpha$-alumina substrate, were $\sim 0.1-0.7$ $\mu \mathrm{m}$ in size with a layer thickness of $\sim 2 \mu \mathrm{m}$. Depositing for a longer time, e.g. $10 \mathrm{~h}$ at $1000^{\circ} \mathrm{C}$ on an $\alpha$-alumina substrate (\#91041, see also Fig. 2), resulted in crystallite sizes of $\sim 2-3 \mu \mathrm{m}$ with a layer thickness of $\sim 5 \mu \mathrm{m}$. Deposition for $6 \mathrm{~h}$ on a $\mathrm{Sr}_{0.15} \mathrm{La}_{0.85} \mathrm{MnO}_{3}$ substrate at $1000^{\circ} \mathrm{C}$ resulted in a $12 \mu \mathrm{m}$ thick layer with crystallite sizes around 2-3 $\mu \mathrm{m}$. According to these results, the trend is that crystallites become larger when the zirconia/yttria layer is thicker. The ratio of layer thickness and crystallite size is approximately the same for all samples mentioned here; only a few crystallites (about three to five across the membrane thickness) and grain boundaries perpendicular to the thickness direction are present. A schematic view is given in Fig. 8. Parallel to the thickness direction many grain boundaries are present. Figure 8 shows that the occurrence of many grain boundaries parallel to the thickness direction gives rise to the formation of columnar structures. This is an important microstructural feature. The influence of EVD process parameters on crystallite size is described more extensively in Ref. 23 for the system zirconia/yttria/terbia.

\section{In situ oxygen permeation}

All in situ oxygen permeation experiments showed a pressure decrease with time in the water chamber, after correction for leakage. The oxygen permeation values $J_{\mathrm{O}}$ were calculated from the slope of the time-dependent pressure change $\mathrm{d} p_{\mathrm{w}} \mathrm{d} t$ in the water chamber via:

$$
J_{\mathrm{O}_{2}}=\frac{V_{\mathrm{WC}}}{R S T_{\mathrm{av}, \mathrm{wc}}} \frac{\mathrm{d} p_{\mathrm{WC}}}{\mathrm{d} t}
$$

where $V_{\mathrm{wc}}$ is the volume of the water chamber (without voluminous metal body $375 \mathrm{~cm}^{3}$; with body $267 \mathrm{~cm}^{3}$ ). $T_{\text {av,wc }}$ is the average temperature in the water chamber during oxygen permeation. When the temperature of the furnace zone in which the sample is located is $700,800,900$ or $1000^{\circ} \mathrm{C}, T_{\text {av,wc }}$ is $51,53,56$ or $59^{\circ} \mathrm{C}$, respectively. $R$ is the gas constant and $S$ is the surface area of the EVD-grown YSZ sample $\left(0.68 \mathrm{~cm}^{2}\right)$. The results that were obtained before decreasing the volume of the water chamber are shown in Table 4.

When the results in Table 4 are inspected, it seems that there is no large influence of the permeation temperature on the permeation value, although permeation at $1000^{\circ} \mathrm{C}$ seems to be somewhat larger than at lower temperatures. The permeation never has a value lower than $0.2 \times 10^{-8} \mathrm{~mol} \mathrm{~cm}^{-2} \mathrm{~s}^{-1}$ (i.e. $0.5 \times 10^{-8}-0.3 \times 10^{-8} \mathrm{~mol} \mathrm{~cm} \mathrm{~cm}^{-2} \mathrm{~s}^{-1}$, see Table 4).

Table 4. In situ oxygen permeation results (without the voluminous body in the water chamber)

\begin{tabular}{lcccc} 
Sample \# & $\begin{array}{c}\text { Deposition time } \\
(\text { min })^{a}\end{array}$ & $\begin{array}{c}\text { Permeation } \\
\text { temperature }\left({ }^{\circ} \mathrm{C}\right)\end{array}$ & $\begin{array}{c}d \mathbf{p}_{\text {wr }} / d \mathrm{~d} \\
\left(\mathrm{mbar} \mathrm{min}^{-1}\right)^{b}\end{array}$ & $\begin{array}{c}\mathrm{J}_{\mathrm{O}_{2}} \\
\left(\mathrm{~mol} \mathrm{~cm}^{-2} \mathrm{~s}^{l}\right)\end{array}$ \\
\hline 91079 & $120^{c}$ & 900 & $-0.016 \pm 0.009$ & $(0.5 \pm 0.3) \times 10^{-8}$ \\
91085 & 30 & 1000 & $-0.030 \pm 0.010$ & $(1 \cdot 0 \pm 0.3) \times 10^{8}$ \\
91088 & 30 & 700 & $-0.014 \pm 0.009$ & $(0.5 \pm 0.3) \times 10^{-8}$ \\
91089 & $30+30$ & 800 & $-0.015 \pm 0.009$ & $(0.5 \pm 0.3) \times 10^{-8}$ \\
91094 & 30 & 1000 & $-0.022 \pm 0.010$ & $(0.7 \pm 0.4) \times 10^{-8}$ \\
\hline
\end{tabular}

"Deposition at $700^{\circ} \mathrm{C}$ on La-doped $\gamma$-alumina membranes under conditions as described in Table 2; all layers have a thickness of $\sim 0.5 \mu \mathrm{m}$ except for $\# 91079$ with thickness $\sim 1 \mu \mathrm{m}$.

${ }^{b}$ Corrected for leakage, i.e. blank subtracted; average leakage $-0.005 \pm 0.003 \mathrm{mbar} \mathrm{min}^{-1}$.

'Continuous deposition.

Table 5. In situ oxygen permeation results (with reduced water chamber volume)

\begin{tabular}{|c|c|c|c|c|c|}
\hline Sample \# & 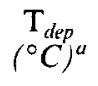 & $\begin{array}{c}\mathrm{t}_{d e p} \\
(\min )^{a}\end{array}$ & $\mathrm{~T}_{\left.\text {perm } ~^{\circ} \mathrm{C}\right)}$ & $\begin{array}{c}d \mathrm{p}_{\mathrm{wd}} d d \mathrm{t} \\
\left(\text { mbar } \text { min }^{-l}\right)^{b}\end{array}$ & $\left(\mathrm{~mol} \mathrm{~cm} \mathrm{O}^{-2} \mathrm{~s}^{-1}\right)$ \\
\hline $91124^{c}$ & 1000 & 120 & 1000 & $\begin{array}{c}-0.12 \pm 0.01 \\
-0.11 \pm 0.01 \\
-0.055 \pm 0.009\end{array}$ & $\begin{array}{l}(3.1 \pm 0.3) \times 10^{-8} \\
(2.8 \pm 0.3) \times 10^{-8} \\
(1.5 \pm 0.3) \times 10^{8}\end{array}$ \\
\hline $91125^{\circ}$ & 1000 & 120 & 1000 & $-0.11 \pm 0.02$ & $(2.8 \pm 0.5) \times 10^{-8}$ \\
\hline $92007^{c}$ & 1000 & 240 & 1000 & $\begin{array}{l}-0.030 \pm 0.007 \\
-0.095 \pm 0.009 \\
-0.012 \pm 0.007\end{array}$ & $\begin{array}{l}(0.8 \pm 0.2) \times 10^{-8} \\
(2.4 \pm 0.3) \times 10^{-8 d} \\
(0.3 \pm 0.2) \times 10^{-8}\end{array}$ \\
\hline $92008^{e}$ & 800 & 120 & 800 & $-0.023 \pm 0.011$ & $(0.6 \pm 0.3) \times 10^{-8}$ \\
\hline $92028^{c}$ & 800 & 120 & 800 & $-0.146 \pm 0.006$ & $(3.7 \pm 0.3) \times 10^{-8}$ \\
\hline
\end{tabular}

"Deposition under conditions as is described in Table 2. Layer thicknesses: \#91124, 2 $\mu \mathrm{m}$; \#91125, 2-3 $\mu \mathrm{m}$; \#92007, 5 $\mu \mathrm{m}$; \#92008, 1 $\mu \mathrm{m}$; \#92028, 1-2 $\mu \mathrm{m}$.

${ }^{\prime}$ Corrected for leakage, i.e. blank subtracted; average leakage $-0.010 \pm 0.005 \mathrm{mbar} \mathrm{min}^{-1}$.

cCoarse porous $\alpha$-alumina substrate.

${ }^{d}$ Oxygen/water mixture at high oxygen partial pressure side.

e La-doped $\gamma$-alumina membrane composite. 
However, the error in each measurement is always $0.3 \times 10^{-8} \mathrm{~mol} \mathrm{~cm}^{-2} \mathrm{~s}^{-1}$ (absolute error) or $30-60 \%$ (relative error), which is too large to give a quantitative trend.

The accuracy was increased by decreasing the volume of the water chamber. In situ oxygen permeation results for this case are shown in Table 5. An EVD experiment (\#91124) was performed in which an $\alpha$-alumina substrate was deposited for $2 \mathrm{~h}$ at $1000^{\circ} \mathrm{C}$ under conditions as described in Table 2. After in situ checking for gas tightness, the deposition was followed by a number of in situ oxygen permeation experiments to control the reproducibility of the measurements. Two permeation experiments were performed at $1000^{\circ} \mathrm{C}$, several hours after the EVD experiment was ended, in the same way as is described in section 'In situ oxygen permeation experiments'. The volume of the water chamber was $267 \mathrm{~cm}^{3}$ and the average temperature in the water chamber was $35^{\circ} \mathrm{C}$. For these two measurements, the leakage corrected pressure decrease in the water chamber was $0.12 \pm$ $0.01 \mathrm{mbar}^{\mathrm{min}}{ }^{-1}$ and $0.11 \pm 0.01 \mathrm{mbar}^{\mathrm{min}}{ }^{-1}$, corresponding to oxygen permeation values of $(3 \cdot 1 \pm$ $0.3) \times 10^{-8}$ and $(2.8 \pm 0.3) \times 10^{-8} \mathrm{~mol} \mathrm{~cm}^{-2} \mathrm{~s}^{-1}$, respectively. An in situ oxygen permeation experiment performed the next day gave a lower value for the oxygen permeation: $(1.5 \pm 0.3) \times 10^{-8} \mathrm{~mol}$ $\mathrm{cm}^{-2} \mathrm{~s}^{-1}$. The experimentally observed decrease in permeation with time for sample \#91124 is probably caused by the fact that the oxygen partial pressure in the metal chloride chamber increases with time. In the beginning, just after the EVD experiment has ended, considerable amounts of metal chlorides may still be present in the metal chloride chamber, for example produced by residual chloride deposits in colder parts of the reactor. This means that the oxygen partial pressure in this chamber is still very low $\left(<<10^{-5} \mathrm{~atm}\right)$, even after flushing for some time with argon or nitrogen. The large oxygen partial pressure gradient over the sample is most probably the reason that the oxygen permeation through the sample is considerably large. In the second permeation measurement, about an hour later, the oxygen partial pressure in the chloride chamber is somewhat increased due to lowered sublimation bed temperatures, flushing with fresh argon and oxygen that gets into the chloride chamber via the in situ oxygen permeation process. The driving force for permeation (i.e. the oxygen partial pressure difference) is now somewhat smaller, so the permeation value will decrease. This effect is even stronger in the permeation experiment performed the next day; the oxygen permeation value is half the value of the previous day.

In situ oxygen permeation experiments were also conducted with another $\alpha$-alumina sample (\#91125) that was deposited under the same conditions (i.e. $2 \mathrm{~h}$ at $1000^{\circ} \mathrm{C}$ ) to control reproducibility. This resulted in a comparable oxygen permeation value of $(2.8 \pm 0.5) \times 10^{-8} \mathrm{~mol} \mathrm{~cm}^{-2} \mathrm{~s}^{-1}$ when the in situ oxygen permeation experiment was performed directly after the EVD experiment. So these in situ oxygen permeation measurements seem to be reproducible.

Of sample \#92007, which had been deposited for $4 \mathrm{~h}$ at $1000^{\circ} \mathrm{C}$ ( $\alpha$-alumina substrate, deposited under conditions as described in Table 2), in situ oxygen permeation measurements were performed with both oxygen $(150 \mathrm{mbar})$ and an oxygen/water mixture $(150$ mbar) at the high oxygen partial pressure side. These experiments were conducted the next day, after decreasing the sublimation bed temperatures and removing the sublimation beds. It can be seen in Table 5 that water has a certain effect on the permeation; the value is about three times higher than the permeation experiment performed with pure oxygen. This indicates that the surface reaction where oxygen (or water) is incorporated into the zirconia/yttria layer may be partly rate-limiting for oxygen permeation under these conditions. When another in situ permeation experiment was performed on this sample, again using pure oxygen at the high oxygen partial pressure side, the permeation value decreased (similar to the observation made for sample \#91124).

Two in situ permeation experiments were performed on samples deposited at $800^{\circ} \mathrm{C}$ under conditions as in Table 2. Sample \#92008 was an La-doped $\gamma$-alumina membrane composite and \#92028 was a coarse $\alpha$-alumina substrate. The oxygen permeation value through the composite was much lower than that measured through the coarse substrate. There is some contradiction in the influence of the oxygen permeation flux by the thickness of the deposited zirconia/yttria layer. Samples \#91124 and \#91125 with a layer thickness of 2-3 $\mu \mathrm{m}$ have a permeation of around $3 \times$ $10^{-8} \mathrm{~mol} \mathrm{~cm}^{-2} \mathrm{~s}^{-1}$ at $1000^{\circ} \mathrm{C}$ while sample $\# 92007$, with a layer thickness of $\sim 5 \mu \mathrm{m}$, has a lower permeation valuc. However, for all samples shown in Table 4 and sample \#92008 in Table 5 the zirconia/yttria layer thickness is around $0.5-1 \mu \mathrm{m}$ while the permeation is lower than for thicker samples. The cause for this contradiction is not clear yet. Probably the morphology of these very thin layers, i.e. the relatively large grain boundary content, is disadvantageous for oxygen permeation properties.

The rate-limiting step for in situ oxygen permeation may be different from the rate-limiting step during EVD layer growth, since there is a difference in experimental conditions. The largest difference is the total pressure at which the processes 
were performed: for EVD layer growth the pressure is 2 mbar, for in situ oxygen permeation it is 150 mbar. Moreover, in in situ oxygen permeation experiments water is (in general) not present at the high oxygen partial pressure side. If diffusion of oxygen through the substrate pores is assumed to be rate-limiting in the temperature range 700 $1000^{\circ} \mathrm{C}$, the oxygen permeation value can be calculated assuming that the oxygen partial pressure in the chloride chamber is negligible compared with the oxygen pressure in the water chamber (150 mbar) and that the porosity and tortuosity values for $\alpha$-alumina substrates are $50 \%$ and 2.5 , respectively. In this case the oxygen permeation ranges from $1.4 \times 10^{-6}$ to $1.6 \times 10^{-6} \mathrm{~mol} \mathrm{~cm}^{-2} \mathrm{~s}^{-1}$ when the temperature decreases from 1000 to $700^{\circ} \mathrm{C}$. These calculated values are much higher (a factor of $\sim 100$ ) than those found in current in situ oxygen permeation experiments (see Tables 4 and $5)$. So, at these relatively high pressures, the diffusion of oxygen through the substrate pores is no longer rate-limiting for oxygen permeation.

Three other steps that can be rate-limiting in the oxygen permeation process are the two surface reactions and the 'bulk' diffusion through the layer. It can be argued that for very thin $(\sim 1 \mu \mathrm{m})$ zirconia/yttria layers one of the surface reaction steps is rate-limiting. Bouwmeester et al. ${ }^{33}$ reviewed the importance of surface exchange reactions as rate-limiting step in the oxygen permeation process through mixed conducting oxides. Dou et $a l .{ }^{34}$ have shown that for calcia-stabilized zirconia pellets under specific conditions, below a certain thickness, surface exchange reactions influence the oxygen permeation value to a large extent. In addition, since water vapour is no longer present (as is the case during the EVD process), the reduction reaction at the oxygen/metal oxide surface will no longer be catalytically activated. It is doubtful, however, whether extrapolation to ultrathin layers is allowed. Effects of microstructure (parallel grain boundaries in columnar-like structures, defects on grain boundaries) become important here. It is stated that in very thin layers $(\sim 0.5$ $\mu \mathrm{m})$ the morphology of the layers becomes important. It is possible that for these thin, columnar grown layers the crystallite size is $\sim 100 \mathrm{~nm}$, so that surface diffusion along the boundaries of the crystallites parallel to the thickness direction is certainly possible. However, it is also possible that grain boundaries perpendicular to the thickness direction can be obstructive for oxygen transport (see Fig. 8).

An attempt has been made to observe oxygen permeation through EVD-grown zirconia/yttria under a small oxygen partial pressure gradient. Therefore, sample \#92001 (deposition for $2 \mathrm{~h}$ at $1000^{\circ} \mathrm{C}$ on an $\alpha$-alumina substrate; duplicate of sample \#91124) was put in an oxygen permeation reactor (more extensively described in Ref. 35) with air $\left(P_{\mathrm{O}_{2}}=0.212 \mathrm{~atm}\right)$ at the high and helium $\left(P_{\mathrm{O}_{2}} \approx 10^{-4} \mathrm{~atm}\right)$ at the low oxygen partial pressure side. At $1100^{\circ} \mathrm{C}$ an oxygen permeation value of $\sim 6 \times 10^{-11} \mathrm{~mol} \mathrm{~cm}^{-2} \mathrm{~s}^{-1}$ was found. Comparing this value with the in situ oxygen permeation value of a similar sample ( $\# 91124$, see Table 5) of $\sim 3 \times$ $10^{-8} \mathrm{~mol} \mathrm{~cm}^{-2} \mathrm{~s}^{-1}$ (at $1000^{\circ} \mathrm{C}$ ) shows that the oxygen partial pressure gradient over the zirconia/yttria membrane has a large influence on the oxygen permeation.

Summarizing, under in situ oxygen permeation conditions for EVD-grown zirconia/yttria layers with thicknesses between 0.5 and $5 \mu \mathrm{m}$, the oxygen permeation flux is influenced by a number of parameters: the layer thickness, the layer morphology, the presence of water and the oxygen partial pressure gradient over the layer. It is very hard to establish the rate-limiting step for oxygen permeation. It is suggested that the rate-limiting step is the electrochemical diffusion through the layer, in combination with the reduction reaction at the oxygen/solid electrolyte layer. It is certain that the diffusion of oxygen through the substrate pores is not rate-limiting under in situ oxygen permeation conditions.

\section{Conclusions}

It is possible to deposit thin $(0 \cdot 5-5 \mu \mathrm{m})$, dense zirconia/yttria layers on porous ceramic substrates. By performing depositions at relatively low temperatures $\left(700-800^{\circ} \mathrm{C}\right)$ and low pressures $(2-5$ mbar) it is possible to grow thinner layers than at $1000^{\circ} \mathrm{C}$

Water vapour enhances the surface reaction rate at the metal oxide/oxygen source reactant interface. In the absence of water in the oxygen source reactant, another step (for example a surface exchange reaction) may be rate-limiting for EVD layer growth. A layer growth rate of $\sim 1.6$ $\mu \mathrm{m} \mathrm{h}^{-1}$ is observed for zirconia/yttria deposited at $1000^{\circ} \mathrm{C}$ and 2 mbar on an $\alpha$-alumina substrate in the presence of water. Diffusion of the oxygen source reactant in the presence of water through the substrate pores is rate-limiting for EVD zirconia/yttria layer growth at $1000^{\circ} \mathrm{C}$ in the Knudsen regime (low pressure, small pores).

Results of kinetic experiments compared with theoretical analysis show that between 900 and $1000^{\circ} \mathrm{C}$ (in the presence of water as oxygen source reactant) a transition occurs from pore diffusion to bulk electrochemical diffusion as the rate-limiting step. Below $900^{\circ} \mathrm{C}$, the bulk electrochemical 
diffusion of oxygen through the EVD layer is the rate-limiting step. At $800^{\circ} \mathrm{C}$, the layer growth rate is very slow, below several tenths of a $\mu \mathrm{m}$ per hour.

SEM and XRD analyses show that zirconia/ yttria is mainly deposited in the cubic yttria-stabilized zirconia phase; relatively small fractions of monoclinic and tetragonal zirconia/yttria are obtained. The layers grow in a typical columnarlike way at high temperatures and are polycrystalline. Crystallites become larger when the zirconia/yttria layer is thicker; for a $0 \cdot 5,2-3$ or 12 $\mu \mathrm{m}$ thick layer, crystallite sizes are around $0 \cdot 1,0.5$ or $2-3 \mu \mathrm{m}$, respectively. Determination of crystallite sizes by means of $\mathrm{X}$-ray line broadening does not give good results due to influences of strain and inhomogencities.

In situ oxygen permeation experiments were performed on the deposited zirconia/yttria layers in the CVD/EVD reactor. Typical conditions are: temperature $700-1000^{\circ} \mathrm{C}$, pressure $150 \mathrm{mbar}$, oxygen and oxygen/water at the high oxygen partial pressure side and argon/metal chloride vapours at the low oxygen partial pressure side. Under these conditions, for EVD-grown zirconia/yttria layers with thicknesses between 0.5 and $5 \mu \mathrm{m}$, the oxygen permeation flux is influenced by factors such as the layer thickness, the layer morphology, the presence of water and the oxygen partial pressure gradient over the layer. Typical permeation values are around $10^{-8} \mathrm{~mol} \mathrm{~cm}^{-2} \mathrm{~s}^{-1}$.

\section{Acknowledgements}

This investigation was supported by the Netherlands Foundation for Chemical Research (SON, project number 700-332-004) with financial aid from the Netherlands Organisation for Scientific Research (NWO).

Mr J. Boeijsma, Ing. C.M. Ophuis and Dr B. A. van Hassel are acknowledged for performing the XRD experiments, a number of CVD/EVD experiments and some of the oxygen permeation experiments, respectively. Dr G. W. Koebrugge is acknowledged for his assistance with AFM analysis; Prof. Dr Ir H. Verweij and Dr G. Z. Cao for many interesting discussions. Ing. M. M. A. Smithers and Dr Ir T. Kachlicki (Centre of Materials Research) are acknowledged for performing HR-SEM and TEM analyses, respectively.

\section{References}

1. Isenberg, A. O., Growth of refractory oxides layers by electrochemical vapor deposition (EVD) at elevated tem- peratures. In Proc. Symp. Electrode Materials, Processes for Energy Conversion and Storage, ed. J. D. E. McIntyre, S. Srinivasan \& F. G. Will. The Electrochem. Soc. Inc., Princeton, NJ, 1977, vol. 77, No. 6, 572-83.

2. Dietrich, G. \& Schäfer, W., Advances in the development of thin-film cells for high temperature electrolysis. Int. J. Hydrogen Energy, 9 (1984) 747-52.

3. Carolan, M. F. \& Michaels, J. N., Chemical vapour deposition of yttria-stabilized zirconia on porous substrates. Solid State Ionics, 25 (1987) 207-16.

4. de Haart, L. G. J., Lin, Y. S., de Vries, K. J. \& Burggraaf, A. J., Modified CVD of nanoscale structures in and EVD of thin layers on porous ceramic membranes. J. Eur. Ceram. Soc., 8|1] (1991) 59-70.

5. Cao, G. Z., Brinkman, H. W., Meijerink, J., de Vries, K. J. \& Burggraaf, A. J., Pore narrowing and formation of ultrathin yttria-stabilized zirconia layers in ceramic membranes by chemical vapour deposition/electrochemical vapour deposition. J. Am. Ceram. Soc., 76[9] (1993) 2201-8.

6. Brinkman, H. W., Cao, G. Z., Meijerink, J., de Vries, K. J. \& Burggraaf, A. J., Modelling and analysis of CVD processes for ceramic membrane preparation. Solid State Ionics, 63-65 (1993) 37-44.

7. Pal, U. B. \& Singhal, S. C., Electrochemical vapor deposition of yttria-stabilized zirconia films. $J$. Electrochem. Soc., 137[9] (1990) 2937-41.

8. Carolan, M. F. \& Michaels, J. N., Growth rates and mechanism of electrochemical vapor deposited yttriastabilized zirconia films. Solid State Ionics, 37 (1990) 189-95.

9. Lin, Y. S., de Vries, K. J., Brinkman, H. W. \& Burggraaf, A. J., Oxygen semipermeable solid oxide membrane composites prepared by electrochemical vapor deposition. J. Membrane Sci., 66 (1992) 211-26.

10. Lin, Y. S., de Haart, L. G. J., de Vries, K. J. \& Burggraaf, A. J. A kinetic study of the electrochemical vapor deposition of solid oxide electrolyte films on porous substrates. J. Electrochem. Soc., 137[12] (1990) 3960-6.

11. de Haart, L. G. J., Lin, Y. S., de Vries, K. J. \& Burggraaf, A. J., On the kinetic study of electrochemical vapour deposition. Solid State Ionics, 47 (1991) 331-6.

12. Schoonman, J., Dekker, J. P., Broers, J. W. \& Kiwiet, N. J., Electrochemical vapor deposition of stabilized zirconia and interconnection materials for solid oxide fuel cells. Solid State Ionics, 46 (1991) 299--308.

13. Kiwiet, N. J. \& Schoonman, J., Electrochemical vapor deposition: theory and experiment. In Proc. 25th Int. Soc. Energy Conv. Eng. Conf., ed. P. A. Nelson, W. W. Schertz \& R. H. Till. AIChE, New York, 1990, Vol. 3, pp. 240-5.

14. Dekker, J. P., Kiwiet, N. J. \& Schoonman, J., Electrochemical vapor deposition of SOFC components. In Proc. lst Int. Symp. on SOFC, High Temp. Mater. Div. Proc. Vol. 89-11, ed. S. C. Singhal. The Electrochemical Society Inc. Pennington, NJ, 1989, pp. 57-66.

15. Dekker, J. P., van Dieten, V. E. J. \& Schoonman, J., The growth of electrochemical vapor deposited YSZ films. Solid State Ionics, 51 (1992) 143-5.

16. Dekker, J. P., van Dieten, V. E. J. \& Schoonman, J., The growth of electrochemical vapor deposited YSZ films. In Science and Technology of Zirconia V, ed. S. P. S. Badwal, M. J. Bannister \& R. H. J. Hannink. Technomic Publishing Company Inc., Lancaster, PA, 1993, pp. 786-802.

17. Sasaki, H., Yakawa, C., Otoshi, S., Suzuki, M. \& Ippommatsu, M., Reaction mechanism of electrochemical-vapor deposition of yttria-stabilized zirconia film. J. Appl. Phys., 74[7] (1993) 4608-13.

18. Han, J. \& Lin, Y. S., An improved analysis on kinetics of electrochemical vapor deposition. Solid State Ionics, 73 (1994) 255-63.

19. Park, J.-H. \& Blumenthal, R. N., Electronic transport in 8 mole percent $\mathrm{Y}_{2} \mathrm{O}_{3}-\mathrm{ZrO}_{2}$. J. Electrochem. Soc., 136[10] (1989) 2867-76. 
20. Lin, Y. S. \& Burggraaf, A. J., Preparation and characterization of high-temperature thermally stable alumina composite membranes. J. Am. Ceram. Soc., 74[1] (1991) 219-24.

21. Cao, G. Z., Meijerink, J., Brinkman, H. W. \& Burggraaf, A. J., Permporometry study on the size distribution of active pores in porous ceramic membranes. J. Membrane Sci., 83 (1993) 221-35.

22. Brinkman, H. W., Cao, G. Z., Meijerink, J., de Vries, K. J. \& Burggraaf, A. J., Kinetics of the EVD process for growing thin zirconia/yttria films on porous alumina substrates. J. Phys. IV Colloque C3, 3 (1993) 59-66.

23. Brinkman, H. W. \& Burggraaf, A. J., Ceramic membranes by electrochemical vapor deposition of zirconia/ yttria/terbia layers on porous substrates. J. Electrochem. Soc., 42[11] (1995) 3851-8.

24. Brinkman, H. W., Cao, G. Z., Meijerink, J., de Vries, K. J. \& Burggraaf, A. J., Morphology of very thin layers made by electrochemical vapour deposition at low temperatures. In Science and Technology of Zirconia $V$, ed. S. P. S. Badwal, M. J. Bannister \& R. H. J. Hannink. Technomic Publishing Company, Inc., Lancaster, PA, 1993, pp. 811-8

25. Wen, C. J. \& Mason, D. M., Electrocatalysis on solid oxide electrolytes. J. Appl. Electrochem., 8 (1978) 81-5.

26. Oberländer, B., Kofstad, P. \& Kvernes, I., On oxygen diffusion in tetragonal zirconia. Mat.-wiss. u. Werkstofftech., 19 (1988) 190 3.

27. Chen, C. S., Boutz, M. M. R., Boukamp, B. A., Winnubst, A. J. A., de Vries, K. J. \& Burggraaf, A. J., The electrical characterization of grain boundaries in ultrafine grained Y-TZP. Mater. Sci. Eng., A168 (1993) 231-4.

28. Toraya, H., Yoshimura, M. \& Somiya, S., Calibration curve for quantitative analysis of the monoclinic-tetragonal $\mathrm{ZrO}_{2}$ system by $\mathrm{X}$-ray diffraction. J. Am. Ceram. Soc., 67 (1984) C119-21.

29. Toraya, H., Yoshimura, M. \& Somiya, S., Quantitative analysis of monoclinic-stabilized cubic $\mathrm{ZrO}_{2}$ systems by X-ray diffraction. J. Am. Ceram. Soc., 67 (1984) C183-4.

30. Brinkman, H. W., Ceramic membranes by (electro)chemical vapour deposition. Investigations on thin film and bulk mixed conducting materials. PhD thesis, University of Twente, Enschede, The Netherlands, 1994, pp. 96-101.

31. Brinkman, H. W., de Haart, L. G. J., Lin, Y. S., de Vries, K. J. \& Burggraaf, A. J., Electrochemical vapour deposited zirconia/yttria layers on porous substrates. In Proc. ECerS '91, 11-14 Sept. 1991, Augsburg, FRG. Euro. Ceram. II, Vol. 3, ed. G. Ziegler \& H. Hausner, 1993, pp. 2375-8.

32. Klug, K. P. \& Alexander, L. E., X-ray diffraction procedures. Wiley \& Sons, New York, 1974, pp. 687-92.

33. Bouwmeester, H. J. M., Kruidhof, H. \& Burggraaf, A. J., Importance of the surface exchange kinetics as rate-limiting step in oxygen permeation through mixed-conducting oxides. Solid State Ionics, 72 (1994) 185-94.
34. Dou, S., Masson, C. R. \& Pacey, P. D., Mechanism of oxygen permeation through lime-stabilized zirconia. $J$. Electrochem. Soc., 132[8] (1985) 1843-9.

35. Bouwmeester, H. J. M., Kruidhof, H., Burggraaf, A. J. \& Gellings, P. J., Oxygen semipermeability of erbia-stabilized bismuth oxide. Solid State lonics, 53-56 (1992) $460-8$.

\section{Notation}

$D \quad$ Crystallite size (nm)

$D_{\mathrm{H}_{2} \mathrm{O}}$ Knudsen diffusion coefficient of water vapour $\left(\mathrm{m}^{2} \mathrm{~s}^{-1}\right)$

$D_{\mathrm{O}_{2}} \quad$ Knudsen diffusion coefficient of molecular oxygen $\left(\mathrm{m}^{2} \mathrm{~s}^{-1}\right)$

$J_{\mathrm{O}_{2}} \quad$ Permeation flux of molecular oxygen (mol $\mathrm{cm}^{-2} \mathrm{~s}^{-1}$ )

$K \quad$ Scherrer constant

$I \quad$ EVD layer thickness $(\mu \mathrm{m})$

$L \quad$ Substrate thickness (mm)

$n_{i} \quad$ Number of oxygen atoms per water $\left(n_{i}=1\right)$ or oxygen $\left(n_{i}=2\right)$ molecule

$P_{i, \text { OSR }}$ Pressure of compound $i$ in the Oxygen Source Reactant mixture $(\mathbf{P a})$

$P_{\mathrm{H}_{2} \mathrm{O}} \quad$ Water vapour (partial) pressure $(\mathrm{Pa})$

$P_{\mathrm{O}} \quad$ Oxygen (partial) pressure $(\mathrm{Pa})$

$P_{\mathrm{wc}}^{2} \quad$ Pressure in water chamber of $\mathrm{CVD} / \mathrm{EVD}$ reactor $(\mathrm{Pa})$

$R \quad$ Gas constant $\left(8.3143 \mathrm{~J} \mathrm{~mol}^{-1} \mathrm{~K}^{-1}\right)$

$S \quad$ Surface area of EVD-grown sample

$T \quad$ Absolute temperature (K)

$T_{\mathrm{av}, \mathrm{wc}}$ Average temperature in water chamber of $\mathrm{CVD} / \mathrm{EVD}$ reactor $\left({ }^{\circ} \mathrm{C}\right)$

$t \quad$ Time (min, s)

$V_{\text {mol }} \quad$ Molar volume (of YSZ) $\left(\mathrm{m}^{3} \mathrm{~mol}^{-1}\right)$

$V_{\text {wc }} \quad$ Volume of water chamber in CVD/EVD reactor $\left(\mathrm{cm}^{3}\right)$

$V_{\mathrm{m}} \quad$ Volume fraction of monoclinic zirconia/ yttria

$\beta \quad$ Half width line broadening $\left(2 \theta^{\circ}\right)$

$\theta \quad$ Diffraction angle $\left({ }^{\circ}\right)$

$\lambda \quad$ Wavelength of X-rays $(\mathrm{nm})$ 